\title{
Commentary
}

\section{Why are the next steps in biomaterials research so difficult?}

Strategically, 'biomaterials research' should be refocusing its science on new areas - but it has not! Traditionally, biomaterials research has been heavily leveraged in 'synthetic biomaterials product-testing', but it should be moving towards 'biological materials and clinical research'. There is an adage (Lubin's Rule) that says 'If another scientist thought your research was more important than his, he would drop what he is doing and do what you are doing' (1). This appropriately describes the struggle of biomaterials' research investigators to try to move into the next age for biomaterials research. There are several historical impediments here, so let's start at the beginning.

Biomaterials research should encompass three major focuses: (i) complete characterization of the structureproperty events within restorative materials (synthetic or biological), (ii) the biological interactions at their interfaces with biological tissues, and (iii) the changing events of the underlying biological tissues. This interplay (materials, interfaces, tissues) has been the unrealized research goal for biomaterials' scientists for many years. To date, the overwhelming focus has been on laboratory characterization material properties. John Keller (pers. comm., Northwestern University, Chicago, IL, USA) once opined that the 'bio' seemed to be missing from 'biomaterials'.

Two important transitions now are underway that begin to address the problems. Firstly, there is increasing pressure to understand interfaces and tissues as part of expanding focus on clinical research for biomaterials. Secondly, there is strong pressure for biomaterials scientists to embrace tissue engineering and move towards the development and testing of true 'biological materials' (2). Both of these transitions are part of the upcoming Journal of Oral Rehabilitation 2006 Summer School Workshop (theme: oral biomaterials - from material science to biology the clinical consequences) on September 20-24 in Bevagna, Italy. Let's consider each of these major transitions more carefully.
Concern for the need for clinical research in biomaterials actually was first emphasized in the mid-1960 s by Ryge (3). While it has been popular in the last decade to call for evidence-based dentistry, the actual push began long ago. In the absence of financial incentives, clinical research has been severely hindered for many years. Despite this problem, Ryge led the effort to put into place a system for collecting information about the clinical performance of restorative materials (USPHS guidelines) that was based on 'direct' patient observations (4). Realizing the possible value of extending direct evaluation methods, Leinfelder (5) and others (6) embarked on using impression techniques to capture intra-oral morphologic data and create working casts for subsequent laboratory analysis of events. This 'indirect' approach has been the primary method for quantitative measurement monitoring of changes such as occlusal wear (7) over the last 25 years. Direct and indirect clinical research methods for restorative materials have only been able to evolve because of the funding support of dental materials manufacturers. Even then, their funding has been very limited in numbers and amounts. The National Institute for Dental and Craniofacial Research (NIDCR), until recently, has shown no interest in supporting clinical research of restorative materials. Since 2002, NIH (8) has declared a strong interest in conducting translational research and includes clinical research under that umbrella. However, that movement so far has been to increase clinical data collection and not to enhance clinical research techniques. Thus, clinical research involving biomaterials continues to be stalled for the short term.

For most of the history of dental biomaterials research, the focus has been on the development and testing of 'synthetic biomaterials'. However, since the mid-1990 s, there has been increasing interest and emphasis (particularly by NIH) in developing and testing 'biological biomaterials' that are associated with tissue engineering. While older biomaterials' scientists may not have much depth in biological science, the materials' science training of these same individuals would seem to position them well to apply those principles in arenas such as tissue engineering. Still, the migration of 
materials' scientists into this area has been arguably slow, at best. The continuing reduction in the number of funded biomaterials' scientists is stark evidence of this trend and unfortunate circumstance. Biomaterials' scientists have fought to a losing battle with NIH to preserve a traditional non-biological focus instead.

Journals and journal editors have watched from the sidelines for several years as these events unfolded. They had hoped for a rapid shift towards clinical research. Journals desire relevant clinical information. The Journal of Oral Rehabilitation, under Peter Svensson's leadership, has clearly refocused its priorities to exclude routine materials testing reports. Readers have demanded more useful information about long-term clinical performance of restorative materials for their own guidance in selection and manipulation. This tug-of-war between authors and readers has not waned. Research reports continue to be strongly dominated by laboratory testing of commercial products. A preliminary examination of product testing levels (9) reported that during the 5- to 15 year product lives of popular dental materials products in such categories as bonding systems, composites, or cements, there has been a remarkable output of '278 research articles per product' generated within the biomedical literature. Materials have been tested and retested. None of these articles focused on complete characterization. Rather, no more than a couple at a time of the forty or more possible physical, chemical, mechanical, or biological properties was ever reported.

The quantity of published biomaterials information continues to escalate. It is not driven by new scientific thrusts. All of the evidence indicates that increasing publication is driven by more of the same old thing, laboratory product testing. Typically, more than 700 publications associated with traditional biomaterials topics appear in the biomedical literature each year (10). An earlier trend analysis (11), pointed out that $>85 \%$ of these articles involved laboratory research results. One might wonder why this should happen if there was such a strong concern about the usefulness of laboratory testing results. Three things seem to dictate against any major change. Firstly, there is very little real clinical research to replace laboratory information. Secondly, new journals are being created every day, need content, and are willing to accept extensive numbers of laboratory studies in the early phases of their operation. A huge number of articles are now published in the scientific literature every day. Third, marketing and sales operations, in the absence of longer term clinical data, thrive on laboratory results as evidence for their new products, and continue to actively provide that research support. Thus, there is no true pressure against continued restorative materials product-testing as a way of life for biomaterials research.

Perhaps another unfortunate consequence of these events is bad timing. The cohort of biomaterials scientists is dominated by individuals in the twilight stages of their careers. They have no interest in being 'reinvented' or 'shifting their focus'. At this moment, the mean age of International Association for Dental Research (IADR) scientists (including biomaterials scientists) is 60.5 years old. More than $50 \%$ of the current biomaterial's scientists could be retired within $5-8$ years. Of the remaining group, one might argue only the youngest portion (perhaps $10-15 \%$ ) has been trained in the new science. Another portion (25-30\%) may still be waiting for career opportunities to refocus their efforts into biological biomaterials. A further portion $(10 \%)$ could be in no-man's land, looking at considering options to abandon their scientific participation in the field entirely for administration and/or teaching. All of this means that far fewer future scientists will be available to conduct the new science of biological biomaterials and even fewer may carry the torch for clinical research for biomaterials.

Where do we go from here? New scientists will shift from synthetic towards biological materials testing. A limited number of new scientists will continue to develop the sophistication of clinical research methods. Research investigations will gradually shift towards understanding the complex intra-oral environment and the shifting interactions of materials, interfaces, and tissues over time. Editors will press for this change by refusing to support the publication of product-testing experiments. If all of these were accompanied by strong research funding, then this new world of research would be fast upon us. However, limited research resources and the loss of many senior investigators will forestall the needed changes.

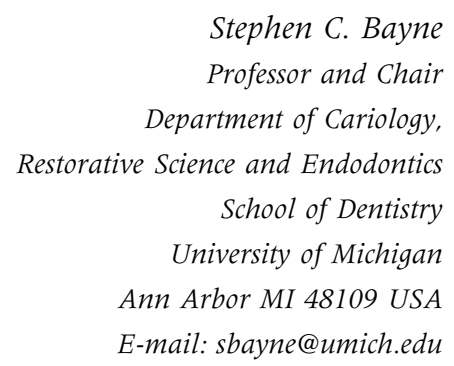

Stephen C. Bayne Professor and Chair Science and Endodontics University of Michigan Ann Arbor MI 48109 USA E-mail:sbayne@umich.edu 


\section{References}

1. Dickson P. Lubin's rule. In: The Official Rules. New York: Delacorte Press; 1978:109.

2. Bayne SC. Bomaterials: where are we and where are we going? Proceedings of distinguished professors symposium. J Dent Ed. 2005;69:571-585.

3. Ryge G. Clinical evaluation of adhesive restorative materials. In: Austin RH, Wilsdorf HGF, Phillips RW, eds. Adhesive Restorative Dental Materials II. Proceedings of a Workshop held at the University of Virginia, Charlottesville, Virginia, December. 1966; National Institute of Dental Research, Public Health Service Publication No 14941965:8-9.

4. Cvar J, Ryge G. Criteria for the clinical evaluation of dental restorative materials. 1971; US DHEW Document, US PHS 790244, Printing Office, San Francisco, pp 1-42 (and reprinted as Cvar J, Ryge G. Reprint of Criteria for the clinical evaluation of dental restorative materials. Clin Oral Invest 2005; 9: 215-252).
5. Kusy RP, Leinfelder KF. In situ replication techniques: I. Preliminary screening and the negative replication technique. J Dent Res. 1977; 56:925-932.

6. Marshall GW, Marker VA, Bayne SC. Replication technique for monitoring intra- oral processes with the SEM. Quintessence Int. 1978;9:1-3.

7. Leinfelder KF, Taylor DF, Barkmeier WW, Goldberg AJ. Quantitative wear measurement of posterior composite resins. Dent Mater. 1986;2:198-201.

8. National Institutes of Health. NIH RoadMap. (http://nihroadmap.nih.gov/). Accessed on 11 June 2006.

9. Bayne SC. Product-testing impact for popular dental materials on biomedical publication levels. J Dent Res. 2006;84. Abstr 1658.

10. Bayne SC, Swift Jr EJ, Thompson JY. Dental materials citations: Part B, July to December 1996. Dent Mater. 1997;13:128-142.

11. Bayne SC, Marshall SJ. 20-year analysis of basic vs applied DMG-IADR research abstracts. J Dent Res. 1999;78:130. Abstr 196. 